\title{
CARDIOPATIA CHAGÁSICA EM CRIANÇAS. RELATO DE DOIS CASOS
}

\author{
Joăo Antonio GRANZO'TTI (1), Gutemberg de Melo ROCHA (2), Jorge Renê Garcia AREVALO (3) e \\ Francisco FERRIOLLI FILHO (4)
}

\section{R E S U M O}

Os Autores apresentam dois casos de cardiopatia chagásica crônica na infância, procedentes da região limítrofe entre os Estados de São Paulo e Minas Gerais. O objetivo é mostrar a possibilidade de contaminação natural da doença na área rural da região da qual as crianças são provenientes, assim como contribuir no entendimento fisiopatológico da Doença de Chagas. Ambos os casos apresentaram insuficiência cardíaca refratária aos recursos terapêticos atuais, evo. luindo para o óbito. São feitos comentários gerais sobre a fisiopatologia da doença, com base na literatura pertinente.

\section{N T R O D U G A $\mathrm{A}$}

O ser humano pode adquirir a doença de Chagas através de diferentes formas de introdução do tripanosoma em seu organismo. A forma de infecção que foi a mais comum, é a penetração do agente etiológico eliminado pelas dejeções dos triatomineos, através de mucosas íntegras ou pelas soluçōes de continuidade da pele, já preexistentes ou ocasionadas pela picada do inseto, CHAGAS ${ }^{3,4}$. No Estado de São Paulo o rociamento com hexaclorohexano, FREITAS 7 teve um efeito bastante favorável; aliada à melhoria das habitaçōes rurais, tornou praticamente inexistentes publicações de transmissão natural da doença de Chagas.

Outros processos de infecção seriam através da transfusão de sangue contaminado obti. do de doadores chagásicos, a transmissão transplancentária de mãe para o filho e a contaminação acidental em laboratórios.
Do ponto de vista epidemiológico e de saúde pública, tem grande importância prátida a diss seminação da doença pelo contacto com triatomíneos infectados, colonizando as habitaçōes humanas, pois são muito remotas as possibilidades de infecção natural do homem fora de seu domicílio.

Em nosso meio assume grande importância a transmissão por transfusão de sangue contaminado TOLEZANO ${ }^{16}$, visto que a transmissão congênita no Brasil restringe-se às publicaçōes de LISBOA ${ }^{5}$, na Bahia, em material de abortos, não sendo encontrada a ocorrên. cia em nati-vivos, embora necessite ser mais procurada.

No Serviço de Pediatria da F.M.R.P.U.S.P., tivemos concomitantemente dois casos fatais de cardiopatia chagásica crônica. Uma das crian. ças tinha procedência atual e remota do Estado

Trabalho realizado no Departamento de Parasitologia, Microbiologia e Imunologia e no Departamento de Ginecologia, Obstétrícia e Pediatria da Faculdade de Medicina de Ribeirão Preto da Universidade de São Paulo, Brasil

(1) Departamento de Ginecologia, Obstetricia e Pediatria da Faculdade de Medicina de Ribeirão Preto da Universidade de São Pauio

(2) e (4) Departamento de Parasitologia, Microbiologia e Imunologia da Faculdade de Medicina de Ribeiräo Preto da Universidade de Săo Paulo

(3) Seção de Eletrocardiografia do Hospital das Clínicas de Rỉbeirăo Preto da Universidade de Săo Paulo 
GRANZOTTI, J. A.; ROCHA, G. de M.; AREVALO, J. R. G. \& FERRIOLLI FILHO, F. - Cardiopatia chagásica em crianças. Relato de dois casos. Rev. Inst. Med. trop. São Paulo 27:341-345, 1985.

de São Paulo, zona rural e não havia recebiđo transfusão de sangue. Outra, oriunda do Estado de Minas Gerais, zona urbana, onde existe ainda a transmissāo natural da doença, FERREIRA ${ }^{6}$.

Por interesse clínico e epidemiológico apre. sentamos os dois casos de cardiopatia chagásica crônica em crianças.

\section{Apresentação dos casos e evolução clínica}

Caso $\mathbf{n}^{\circ} 1$ - M.M.F.S. - Idade: 11 a, sexo masculino. Cor branca. Proceđência atual e remota - zona rural de Pedregulho - SP.

Peso: $34.700 \mathrm{~g}-$ Estatura: $144 \mathrm{~cm}$.

A criança foi atendida em 12-1-83, neste hospital, com insuficiência cardíaca e carciiopatia. Esteve internada até 10-3-83, tendo sido feito o diagnostido de cardiopatia chagásica. Medicada neste período com digoxina e diuréticos, recebeu alta em condições favoráveis. Foi reinternada no dia 26-283, por ter apresentado acidente vascular cerebral isquemico trom boembólico, e se encontrava em insuficiência cardíaca. Após 10 dias teve alta, compensada da insuficiência cardíaca e com hemiplegia à direita. Em 27-4-83, compareceu ao ambulatório de Cardiologia infantil com insuficiência cardíaca e hemiplégico à direita. Foi reinternada.

Inicialmente recebeu diuréticos e digital, mantendo-se razoavelmente compensada, não obstante as importantes arritimias cardíacas (extrasistolia ventricular frequientes). Medicada com amiodarona, no entanto, não houve resposta. No dia 13-5, a criança entrou em edema agươo de pulmāo, sendo necessário o uso de dopamina, lidocaína, nipride e isuprel. Após reversăo do quadro agudo foi novamente digi. talizado e introduzido outro antiarrítmico, a disopiramida. Manteve-se até 12-6 ocasião em que teve um novo edema agudo de pulmăo revertido na Unidade de Terapia Intensiva. Revertido o episódio de edema agudo de pulmāo passou-se a usar a dopamina endovenosa, suspendendo-se a droga eme 24-6. Manteve-se o uso de cloridrato de prozosin, indicado com $o$ objetivo de reduzir a pós-carga; a criança evoluiu parcialmente compensada, porém com o estado geral deteriorando, com perda de peso progressiva, não obstante as medidas de suporte nutricional. Faleceu no dia 27-7.83.

\section{Resultados de exames}

Caso n. 1 - M.M.F.S.

a) Pesquisa direta pela técnica da gộta espêssa, para encontro do Trypanosoma cruzi, efetuada várias vezes, negativa.

b) Xenodiagnóstico - Usou-se 40 ninfas de $4 .^{\circ}$ estádio de Triatoma infestans, divididas em 10 por caixa. Leitura após 40 dias positivio em 2 ninfas de cada caixa.

c) Reações sorológicas - Reação de imunofluorescência indireta para Doença de Chagas - Reagente à diluição de $1 / 640$. Reaçāo de fixaçăo de complemento para Doença de Chagas (Machado-Guerreiro) Reagente maior que 3,0.

\section{Eletrocardiograma}

Bloqueio A.V. - 2. grau WENCHEBACH Hemibloqueio anterior esquerdo

Extrasistolia ventricular

Flütter - atrial

Área elétrica inativa anterior

Caso n." 2 - J.G.C., idade: 8 a, sexo: Fe. minino; Cor branca.

procedência atual e remota: São Sebastiáo do Paraíso, $M G$ - Zona Urbana.

Peso: $18.7100 \mathrm{~g}$.

A paciente foi internada em 24-583, com quadro de insuficiência cardíaca congestiva e cardiopatia a esciarecer. Recebeu tratamento com digitálicos e diuréticos. A criança evoluiu regularmente, sem no entanto apresentar completa compensação cardíaca. $\mathrm{Em} \mathrm{10-6-83} \mathrm{a} \mathrm{crian-}$ ça fez embolização da artéria femural direita. Foi submetida a embolectomia, com boa evolução. Durante a evolução na enfermaria, apresentou quadro pneumônico à direita. Não obstante, 0 tratamento instituido, a paciente não apresentou boa evolução e em 29683 , fez quadro de edema agudo pulmonar. Foi iniciado o uso de dopamina e posteriormente e durante um período de 5 a 6 dias, de cloridrato de prazosin.

A criança continuou evoluindo mal, com pobre respostá ac uso de digital. Devido ao quadro de insuficiência cardíaca congestiva, manteve-se o uso da dopamina endovenoso. Foi a. óbito no dia 11-7-83. 
GRANzOTT, J. A:; ROCHA, G. de M.; AREVALO, J. R. G. \& PERRIOLLI FU.HO, F. - Cardiogatia chagásica em crianças. Relato de dols casos. Rev. Inst. Med. trop. Säo Paulo z7:341.345, 1905.

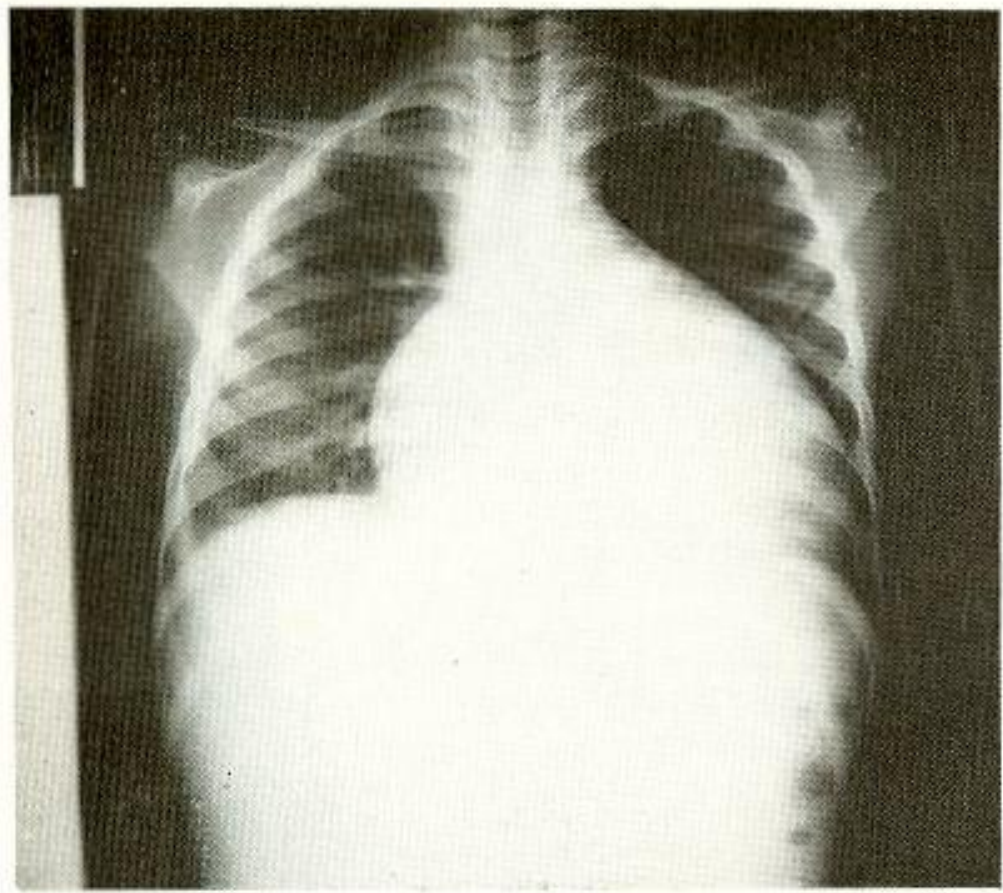

Fig. 1 - Paciente: M. M. F. S. - radiografia da àrea cardiace na posiçào póstero-anterior mostrando a importante cardiomegalis global $++t$, em indice cardio-toricico de 0,68 e intensa congestão pulmonar Ececardiograma

Hipocinesia acentuada do septo in terventricular e parede posterior do ventriculo esquerdo. Dilataçito do ventriculo esquerdo, ventriculo di relto e auricula esquerda. Sinais de aumento de $\mathrm{pD}=$ de ventriculo esquerdo. Déficit acentuado da fun. çao contratil de ventriculo esquendo.

\section{Resultado de Exames}

a) Pesquisa direta pela técnica da gôta espessa, para encontro do Trypanosoma cruzi, foi negativa.

b) Xenodiagnóstico - Usou-se 30 ninfas do $40^{\circ}$ estádio de Triatoma infestans com 10 ninfas por caixa de aplicação. Feita a procura de $\mathbf{T}$. cruzi, após 40 dias, encontram-se $3 / 30$ positivas.

c) Diagnóstico sorológice - Reaçăo de imunofluorescência indireta para Doença de Chagas - REAGEINTE (năo foi titulada). Rea. çăo de fixação de complemento para Doença de Chagas (Machado-Guerreiro) - REAGENTE, TITULO - maior que 3,0 .

\section{Ecoeardiograna}

a) Dilatação moderada de ventrículo esquerdo, ventriculo direito e auricula esquerda.

b) Sinais de diminuiçăo do inotropismo de ventrículo direito.

c) Hipocinesia acentuada da parede posterior do ventriculo esquerdo.

\section{DISCUSSAOO}

Na literatura cientifica a respeito da cardiopatia chagásica, encontramos relatos somente de casos de individuos adultos, desde que a infecçāo aguda causada pelo Trypanosoma cru. zi, pode ser assintomática ou oligossintomática TEIXEIRA 15. Assim, segundo o que se entende da patogenia da Doença de Chagas, as mani festaçōes cardiacas e digestivas, seriam res. postas tardias à infecção aguda KOBERLE 10,11 Na cardiopatia chagásica crônica, o substrato anátomo-patológico é a desnervaçāo autonômica e destruiçâo do miocárdio com substituiçăo fibrótica em ausência do parasita in situ TEI. XEIRA 15 , KOBERLE 10 , ANDRADE 1.

Portanto, pelo que se conhece da doença, as manifestaçōes cardiacas, são geralmente tar. dıas à infecção aguda. Durante as fases aguda e crônica, ocorre a destruiçăo do sistema nervoso intracardiaco, como um processo inflama. tório destrutivo que, segundo as mais recentes pesquisas, relaciona a cardiopatia chagásica crô nica com fenômenos de auto-imunidade TEIXEIRA10, RIBEIRO 13.14, Em recente trabalho experimental TEIXEIRA \& col. ${ }^{25}$, reproduziram em coelhos a Doença de Chagas na sua forma aguda, constatando que após o chagoma de inoculação, desenvolvia-se a cardiopatia chagásica e que a parasitemia dos coelhos detectados por xenodiagnóstico foi positiva, durante 90 dias consecutivos, em valores decrescentes. O pico de parasitemia ocorreu em torno do 10. 
GRANzoTTI, J. A.; ROCHA, G, de M.; AREVALO, J. R. G. \& FERRIOLli FILHO, F. - Cardiopatia chagásica em crianģas Relato de dois casos. Rev. Inst. Med. trop. Săo Paulo 27:341-345, 1985.

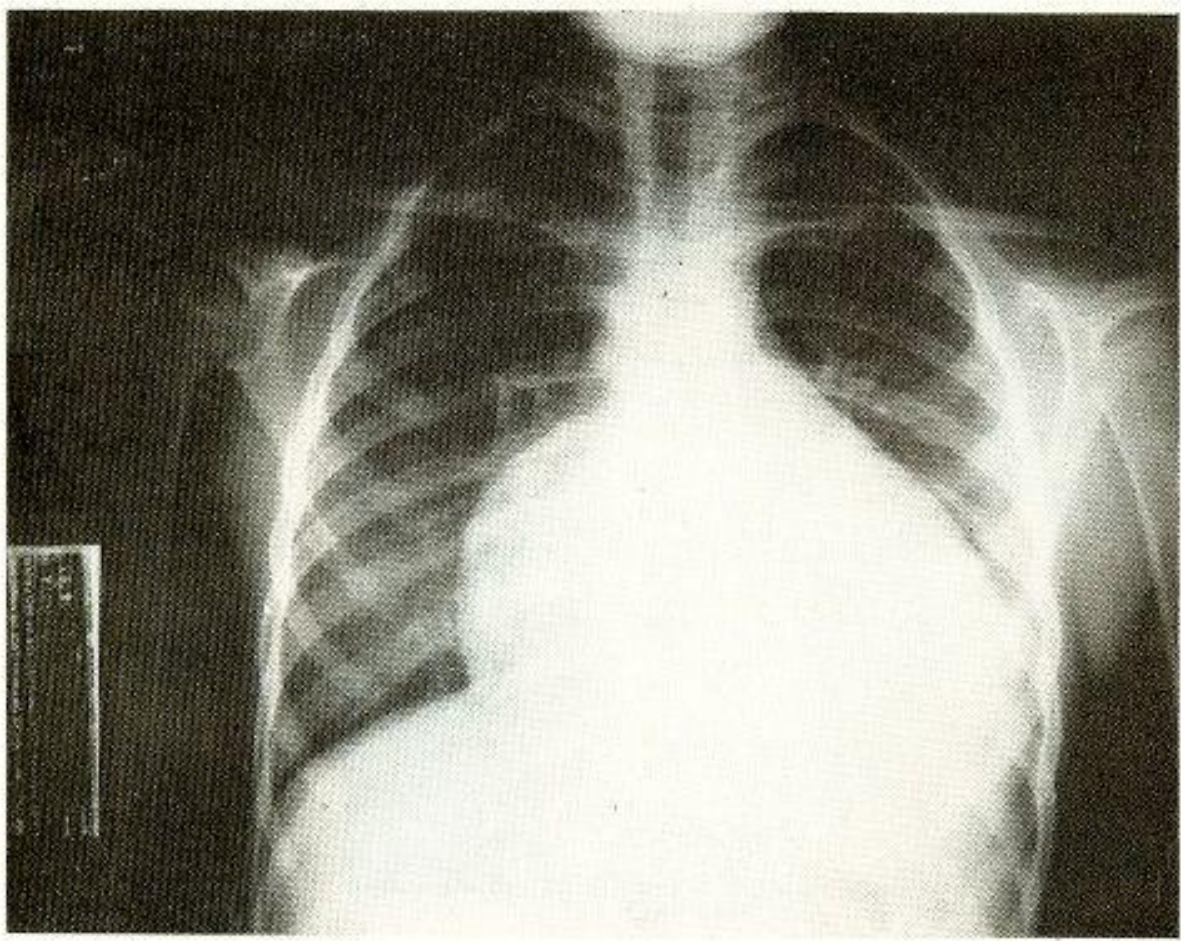

Fig. 2 - Paclente J. G. C. - Radiografia da área cardiaca na posiçăo póstero-anterior mostrandc cardiomegalia global $+f$, com indice cardio-torácico 0.73 e importante congestāo pulmonar. Eletrocardiograma

A) Bloqueio de ramo direito. B) Taquicardia simusal. C) Sobrecarga ventricular direita.

dia da infecçāo, ocorrendo a seguir queda progressiva da parasitemia. No $900^{\circ}$ dia após a infecção, não mais se detectavam coelhos com xenodiagnóstico positivo, porém é desconhe. cido o tempo entre a infecção $e$ as manifestaçōes clínicas da doença.

Quanto ao ponto de vista clínico, ambos os casos são de extrema gravidade, desde que a insuficiência cardiada foi gravissima e refratária a todos os recursos terapêuticos.

Os achados ecocardiográficos, são compatíveis com o diagnóstico de miocardiopatia congestiva, e os eletrocardiográficos com des. criçōes anteriores já publicadas a respeito de cardiopatia chagásica KOBERLE10,11, GRAN. ZOTTI 9, CARVALHO ${ }^{2}$.

Merece destaque a discussão do tema sob o aspecto epidemiológico, visto que a expecta tiva era de, no Estado de Sắo Paulo, năo exis. tir mais casos autoctones. Um deles era pro. cedente de Pedregulho (S.P.) zona rural, portanto, dentro da zona em que se considera ex- tinta a transmissão natural da doença. No en tanto, há de se supor, pela história epidemiols. gica de ambos, que a infecção foi adquirida pelo meio natural de transmissăo. Claro fica, da história clínica, que a transmissão da doença não pode ter sido feita por transfusão de san. gue contaminado, haja visto que nenhuma das crianças recebeu previamente transfusåo sangưinea. Assim, há de se admitir a presença na regiăo, ainda que esporadicamente, de casos isolados de infecção aguda da Doença de Cha. gas.

Sob o ponto de vista dos achados anáto mo-patológicos, estes eståo de acordo com a literatura KÓBERLE 10,11, ANDRADE1. Ambos os casos apresentaram os achados clássicos de miocardiopatia chagásica cro̊nica, sendo que um deles (caso 1), apresentava o típico "aneu risma" da ponta, lesão esta já anteriormente bem estudada ANDRADE ', FONTES s, FERREIRA 5 .

Se por um lado, aceitarmos as novas evidências da existéncia de uma participação imunoló- 
GRANZO'TTI, J. A.; ROCHA, G. de M.; AREVALO, J. R. G. \& FERRIOLLI FILHO, F. - Cardiopatia chagásica em crianças. Relato de dois casos. Rev. Inst. Med. trop. São Paulo 2\%:341-345, 1985.

gica determinando as lesōes cardíacas, temos que aceitar que estas podem ocorrer em um períođo relativamente curto, entre a infecção aguda e as manifestações de miocardite crôni. ca.

Assim, ambos os casos apresentaram lesões cardiacas graves, que, não obstante a utilização de todos os recursos terapêuticos disponiveis, evoluiram para o óbito.

Há também que se referir ao fato de ambos os casos apresentarem acidente vascular embólico. Um deles apresentou embolia da artéria femural e o outro acidente vascular cerebral isquêmico, tipo embólico, fato este também incomum em crianças.

Assim, a nossa expectativa é de, com a descrição destes dois casos de cardiopatia cha. gásica em crianças, contribuir em alertar a respeito da presença da infecção aguda em nosso meio e contribuir para melhor entendimento da patologia da Doença de Chagas.

\section{SUMMARY}

\section{Chagas heart disease in children. Report of two cases}

The Authors report two cases of chronic Chagas'heart disease. The children came from the States of São Paulo and Minas Gerais. The purposes of the report are to discuss the pos. sibility of natural contamination in rural areas in those regions of the states from which the children came, and also to contribute to the knowledge of the physiopathologic aspects of Chagas' heart disease. Both cases presented cardiac failure and did not respond to current therapeutic treatment and they died of uncontrolled cardiac failure. The Authors comment in a general way on the phisiopathology of the disease based on pertinent literature.

\section{REFERENGIAS BIBLIOGRAFICAS}

1. ANDRADE, Z. A. \& ANDRADE, S. G. - Chagas' Disease (American Trypenosomiases). In: Pathology of Protozeol and Helminthic Disease. Ed. Marcial Rojas, R. A. Baltimore, Willians C., 1971, pág. 61.

2. CARVALFAL, S.; PORTUGAL, O.; POLADINO, N.; YUNES, A. \& CAMPOS FILHO, C. - Alterações do
Complexo QRS, nas derivações precordiais e seu substrato anatômico em pacientes portadores de miocardite chagásica crônica. Rev. Paul. Med. 45: 161, 1954.

3. CHAGAS, C. - Nova entidade móxbida do homern. Resumo geral dos estudos etiológicos e clínicos. Mem. Ynst. Oswaldo Cruz 3: 210, 1911.

4. CHAGAS, C. - Tripanossomiase Americana - Forma aguda da Moléstia. Mem. Inst. Oswaldo Cruz 8: 37, 1916.

5. FERREIRA, C. S.; LOPES, E. R.; CHAPADEIRO, E.; SOUZA, W. F. \& ROCHA, A. - Ventriculografia póstmortem na Cardiopatia Chagásica crônica. Correlaçăo anatômica-radiológica. Arq. Bras. Card. 36: 165-170, 1981.

6. FERREIRA, H. - Informação pessoal.

7. FREITAS, J. L. P. - Importância do expurgo selețivo dos domicílios e anexos para a profilaxia da Moléstia de Chagas. Arq. Hig. Saúde Pública 28: 217-272, 1963.

8. FONTES, V. F.; SOUZA, J. E. M.; KORMAN, D. S. \& JATENE, A. - Avaliação cineangiográfica da cardiopatia chagásica crônica. Arq. Bras. Card. 25: 375, 1972.

9. GRANZOTTI, J. A.; MARIN, J. A.; GALLO, L. G.; MANÇO, J. C. \& AMORIN, D. S. - Contribuiçăo ao estudo do "Aneurisma" da ponta na cardiopatia cha. gásica crônica. Arq. Bras. Card. 27: 477-487, 1974.

10. KöbERLE, F. - Patogenia na Moléstia de Chagas. Medicina (CARL) 7: 13, 1962.

11. KöBERLE, F, - Chagas'Disease and Chagas'Syndromes: The pathology of American Trypanosomiasis. Adv, Parasitol. 6: $63 \cdot 116,1968$.

12. LISBOA, A. C. - Sobre a forma congênita da Doença de Chagas. Estudo Anátomo-Patológico de 6 casos. Rev. Inst. Med. trop. São Paulo 2: 319-334, 1960.

13. RIBEIRO, R. S.; OLIVEIRA, J. C. R. \& KÖBERLE, F. - Aspectos imunológicos da destruição neuronal na moléstia de Chagas. Rev. Goiana Med. 22: 235, 1976.

14. RIBEIRO, R. S. \& HUDSON, L. - Trypanosoma cruzi - Immunological consequences of parasite modification of host cell. Clin. Exp. Immunol. 40: 36, 1980.

15. TEIXEIRA, A. R. L.; JUNQUEIRA, L. F.; SOLORZONO, E. \& ZAPPALA, M. - Doença de Chagas em coelhos isogênicos III/J. I - Fisiopatologia das arritimias e morte súbita do chagásico. Rev. Ass. Med. Bras. 29: 77, 1983.

16. TOLEZANO, J. E.; VEDA, E.; MITSUKO, H.; PASCHOAL, S. M. P.; MORAES, C. R.; MARTINS, M. A. \& LIMA, M. A. P. - A tripanossomiase Americana e sua transmissăo transfusional. Rev. Inst. Adolfo Lutz 40: $83 \cdot 88,1980$.

Recebido para publicação em $31 / 8 / 1984$. 